\title{
An Estimate of Referent of Noun Phrases in Japanese Sentences
}

\author{
Masaki Murata \\ Communications Research Laboratory \\ 588-2, Iwaoka, Nishi-ku, Kobe, 651-2401, Japan
}

Abstract

In machine translation and man-machine dialogue, it is important to clarify referents of noun phrases. We present a method for determining the referents of noun phrases in Japanese sentences by using the referential properties, modifiers, and possessors ${ }^{1}$ of noun phrases. Since the Japanese language has no articles, it is difficult to decide whether a noun phrase has an antecedent or not. We had previously estimated the referential properties of noun phrases that correspond to articles by using clue words in the sentences (Murata and Nagao 1993). By using these referential properties, our system determined the referents of noun phrases in Japanese sentences. Furthermore we used the modifiers and possessors of noun phrases in determining the referents of noun phrases. As a result, on training sentences we obtained a precision rate of $82 \%$ and a recall rate of $85 \%$ in the determination of the referents of noun phrases that have antecedents. On test sentences, we obtained a precision rate of $79 \%$ and a recall rate of $7 \pi \%$.

\section{Introduction}

This paper describes the determination of the referent of a noun phrase in Japanese sentences. In machine translation, it is important to clarify the referents of noun phrases. For example, since the two "OJIISAN (old man)" in the following sentences have the same referent, the second "OJIISAN (old man)" should be pronominalized in the translation into English.

\section{OJIISAN-WA JIMEN-NI KOSHI-WO-OROSHITA. \\ (old man) (ground) (sit down) \\ (The old man sat down on the ground.) \\ YAGATE OJIISAN-WA NEMUTTE-SHIMATTA. (soon) (old man) (fall asleep) \\ (He (= the old man) soon fell asleep.)}

When dealing with a situation like this, it is necessary for a machine translation system to recognize that the two "OJIISAN (old man)" have the same referent. In this paper, we propose a method that determines the referents of noun phrases by using (1) the referential properties of noun phrases, (2) the modifiers in noun phrases, and (3) the possessors of entities denoted by the noun phrases.

\footnotetext{
${ }^{1}$ The possessor of a noun phrase is defined as the entity which is the owner of the entity denoted by the noun phrase.
}

\author{
Makoto Nagao \\ Kyoto University \\ Yoshida-Honmachi, Sakyo, Kyoto 606-01, Japan
}

For languages that have articles, like English, we can use articles ("the", "a", and so on) to decide whether a noun phrase has an antecedent or not. In contrast, for languages that have no articles, like Japanese, it is difficult to decide whether a noun phrase has an antecedent. We previously estimated the referential properties of noun phrases that correspond to articles for the translation of Japanese noun phrases into English (Murata and Nagao 1993). By using these referential properties, our system determines the referents of noun phrases in Japanese sentences. Noun phrases are classified by referential property into generic noun phrases, definite noun phrases, and indefinite noun phrases. When the referential property of a noun phrase is a definite noun phrase, the noun phrase can refer to the entity denoted by a noun phrase that has already appeared. When the referential property of a noun phrase is an indefinite noun phrase or a generic noun phrase, the noun phrase cannot refer to the entity denoted by a noun phrase that has already appeared.

It is insufficient to determine referents of noun phrases using only the referential property. This is because even if the referential property of a noun phrase is a definite noun phrase, the noun phrase does not refer to the entity denoted by a noun phrase which has a different modifier or possessor. Therefore, we also use the modifiers and possessors of noun phrases in determining referents of noun phrases.

In connection with our approach, we would like to emphasize the following points:

- So far little work has been done on determining the referents of noun phrases in Japanese.

- Since the Japanese language has no articles, it is difficult to decide whether a noun phrase has an antecedent or not. We use referential properties to solve this problem.

- We determine the possessors of entities denoted by noun phrases and use them like modifiers in estimating the referents of noun phrases. Since the method uses the sematic relation between an entity and the possessor, which is a languageindependent knowledge, it can be used in any other language.

\section{Referential Property of a Noun Phrase}

The following is an example of noun phrase anaphora. "OJIISAN (old man)" in the first sen- 
tence and "OJIISAN (old man)" in the second sentence refer to the same old man, and they are in anaphoric relation.

\section{OJIISAN TO OBAASAN-GA SUNDEITA. (an old man) (and) (an old woman) (lived)}

(There lived an old man and an old woman.)

OJIISAN-WA YAMA-HE SHIBAKARI-NI ITTA. (old man) (mountain) (to gather firewood) (go) (The old man went to the mountains to gather firewood.)

When the system analyzes the anaphoric relation of noun phrases like these, the referential properties of noun phrases are important. The referential property of a noun phrase here means how the noun phrase denotes the referent. If the system can recognize that the second "OJIISAN (old man)" has the referential property of the definite noun phrase, indicating that the noun phrase refers to the contextually non-ambiguous entity, it will be able to judge that the second "OJIISAN (old man)" refers to the entity denoted by the first "OJIISAN (old man). The referential property plays an important role in clarifying the anaphoric relation.

We previously classified noun phrases by referential property into the following three types (Murata and Nagao 1993).

$$
\text { NP }\left\{\begin{array}{l}
\text { generic NP } \\
\text { non generic NP }\left\{\begin{array}{l}
\text { definite NP } \\
\text { indefinite NP }
\end{array}\right.
\end{array}\right.
$$

Generic noun phrase A noun phrase is classified as generic when it denotes all members of the class described by the noun phrase or the class itself of the noun phrase. For example, "INU(dog)" in the following sentence is a generic noun phrase.

$$
\begin{aligned}
& \text { INU-WA YAKUNI-TATSU. } \\
& \text { (dog) (useful) } \\
& \text { (Dogs are useful.) }
\end{aligned}
$$

A generic noun phrase cannot refer to the entity denoted by an indefinite or definite noun phrase. Two generic noun phrases can have the same referent.

Definite noun phrase A noun phrase is classified as definite when it denotes a contextually nonambiguous member of the class of the noun phrase. For example, "INU(dog)" in the following sentence is a definite noun phrase.

$$
\begin{array}{ll}
\begin{array}{l}
\text { INU-WA } \\
\text { (dog) }
\end{array} \begin{array}{ll}
\text { MUKOUHE } & \text { ITTA) } \\
\text { (The dog went away.) } & \text { (go) }
\end{array} \\
\hline
\end{array}
$$

A definite noun phrase can refer to the entity denoted by a noun phrase that has already appeared.
Indefinite noun phrase An indefinite noun phrase denotes an arbitrary member of the class of the noun phrase. For example, "INU(dog)" in the following sentence is an indefinite noun phrase.

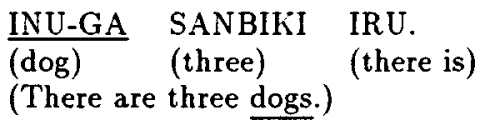

An indefinite noun phrase cannot refer to the entity denoted by a noun phrase that has already appeared.

\section{How to Determine the Referent of a Noun Phrase}

To determine referents of noun phrases, we made the following three constraints.

1. Referential property constraint

2. Modifier constraint

3. Possessor constraint

When two noun phrases which have the same head noun satisfy these three constraints, the system judges that the two noun phrases have the same referent.

\subsection{Referential Property Constraint}

First, our system estimates the referential property of a noun phrase by using the method described in one of our previous papers (Murata and Nagao 1993). The method estimates a referential property using surface expressions in the sentences. For example, since the second "OJIISAN (old man)" in the following sentences is accompanied by a particle "WA (topic)" and the predicate is in the past tense, it is estimated to be a definite noun phrase.

\section{OJIISAN-WA JIMEN-NI KOSHI-WO-OROSHITA \\ (old man) (ground) (sit down) \\ (The old man sat down on the ground.)}

YAGATE OJIISAN-WA NEMUTTE-SHIMAIMATTA. (soon) (old man) (fall asleep)

( $\underline{\text { He }}$ soon fell asleep.)

Next, our system determines the referent of a noun phrase by using its estimated referential property. When a noun phrase is estimated to be a definite noun phrase, our system judges that the noun phrase refers to the entity denoted by a previous noun phrase which has the same head noun. For example, the second "OJIISAN" in the above sentences is estimated to be a definite noun phrase, and our system judges that it refers to the entity denoted by the first "OJIISAN".

When a noun phrase is not estimated to be a definite noun phrase, it usually does not refer to the entity denoted by a noun phrase that has already been 
mentioned. Our method, however, might fail to estimate the referential property, so the noun phrase might refer to the entity denoted by a noun phrase that has already been mentioned. Therefore, when a noun phrase is not estimated to be a definite noun phrase, our system gets a possible referent of the noun phrase and determines whether or not the noun phrase refers to it by using the following three kinds of information.

- the plausibility $(P)$ of the estimated referential property that is a definite noun phrase When our system estimates a referential property, it outputs the score of each category (Murata and Nagao 1993). The value of the plausibility $(P)$ is given by the score.

- the weight $(W)$ of the salience of a possible referent

The weight $(W)$ of the salience is given by the particles such as "WA (topic)" and "GA (subject)". The entity denoted by a noun phrase which has a high salience, is easy to be referred by a noun phrase.

- the distance $(D)$ between the estimated noun phrase and a possible referent

The distance $(D)$ is the number of noun phrases between the estimated noun phrase and a possible referent.

When the value given by these three kinds of information is higher than a given threshold, our system judges that the noun phrase refers to the possible referent. Otherwise, it judges that the noun phrase does not refer to the possible referent and is an indefinite noun phrase or a generic noun phrase.

\subsection{Modifier Constraint}

It is insufficient to determine referents of noun phrases by using only the referential property. When two noun phrases have different modifiers, they usually do not have the same referent. For example, "MIGI(right)-NO HOO(cheek)" and "HIDARI(left)-NO HOO(cheek)" in the following sentences do not have the same referent.

KONO OJIISAN-NO KOBU-WA MIGI-NO HOO-NI ATTA. (this) (old man) (lump) (right) (cheek) (be on) (This old man's lump was on his right cheek.)

TENGU-WA, KOBU-WO HIDARI-NO HOO-NI TSUKETA. (tengu) $^{2} \quad$ (lump) (left) (cheek) (put on)

(The "tengu" put a lump on his left cheek)

Therefore, we made the following constraint: A noun phrase that has a modifier cannot refer to the

\footnotetext{
${ }^{2} \mathrm{~A}$ tengu is a kind of monster.
}

entity denoted by a noun phrase that does not have the same modifier. A noun phrase that does not have a modifier can refer to the entity denoted by a noun phrase that has any modifier.

The constraint is incomplete, and is not truly applicable to all cases. There are some exceptions where a noun can refer to the entity of a noun that has a different modifier. But we use the constraint because we can get a higher precision than if we did not use it.

\subsection{Possessor Constraint}

When a noun phrase has a semantic marker PAR (a part of a body), ${ }^{3}$ our system tries to estimate the possessor of the entity denoted by the noun phrase. We suppose that the possessor of a noun phrase is the subject or the noun phrase's nearest topic that has a semantic marker HUM (human) or a semantic marker ANI (animal). For example, we examine two instances of "HOO (cheek)" in the following sentences, which have a semantic marker PAR.

$$
\begin{aligned}
& \text { OJIISAN-NIWA [OJIISAN-NO] }{ }^{4} \text { HIDARI-NO } \\
& \text { (old man) (left) } \\
& \text { HOO-NI KOBU-GA ATTA. } \\
& \text { (cheek) (lump) (be on) } \\
& \text { (This old man had a lump on his left cheek.) } \\
& \text { SORE-WA KOBUSHI-HODO-NO KOBU-DATTA. } \\
& \text { (it) (person's fist) (lump) } \\
& \text { (It is about the size of a person's fist.) } \\
& \begin{array}{lll}
\text { OJIISAN-GA } & \text { [OJIISAN-NO] } & \frac{\text { HOO-WO }}{\text { (old man (subject)) }} \\
\text { (old man's) } & \text { (cheek) }
\end{array} \\
& \text { HUKURAMASETE IRUYOUNI-MIETA. } \\
& \text { (puff) (look as if) } \\
& \text { (He looked as if he had puffed out his cheek.) }
\end{aligned}
$$

The possessor of the first "HOO (cheek)" is determined to be "OJIISAN (old man)" because "OJIISAN (old man)", which has a semantic marker HUM (human), is followed by a particle "NIWA (topic)" and is the topic of the sentence. The possessor of the second "HOO (cheek)" is also determined to be "OJIISAN (old man)" because "OJIISAN (old man)" is the subject of the sentence.

We made the following constraint, which is similar to the modifier constraint, by using possessors. When the possessor of a noun phrase is estimated, the noun phrase cannot refer to the entity denoted by a noun phrase that does not have the same possessor. When the possessor of a noun phrase is not estimated, the noun phrase can refer to the entity denoted by a noun phrase that has any possessor.

\footnotetext{
${ }^{3}$ In this paper, we use the Noun Semantic Marker Diction nary (Watanabe et al.1992).

4 The words in brackets [] are omitted in the sentences.
} 
For example, since the two instances of "HOO (cheek)" in the above sentences have the same possessor "OJIISAN (old man)", our system correctly judges that they have the same referent.

\section{Anaphora Resolution System}

\subsection{Procedure}

Before referents are determined, sentences are transformed into a case structure by the case structure analyzer (Kurohashi and Nagao 1994).

Referents of noun phrases are determined by using heuristic rules which are made from information such as the three constraints mentioned in Section 3. Using these rules, our system takes possible referents and gives them points. It judges that the candidate having the maximum total score is the referent. This is because a number of types of information are combined in anaphora resolution. We can specify which rule takes priority by using points.

The heuristic rules are given in the following form.

Condition $\Rightarrow\{$ Proposal Proposal .. $\}$

Proposal $:=($ Possible-Referent Point $)$

Here, Condition consists of surface expressions, semantic constraints and referential properties. In Possible-Referent, a possible referent, "Indefinite", "Generic", or other things are written. "Indefinite" means that the noun phase is an indefinite noun phrase, and it does not refer to the entity denoted by a previous noun phrase. Point means the plausibility value of the possible referent.

4.2 Heuristic Rule for Estimating Referents We made 8 heuristic rules for the resolution of noun phrase anaphora. Some of them are given below.

$\mathrm{R} 1$ When a noun phrase is modified by the words "SOREZORE-NO (each)" and "ONOONO-NO (each)", \{(Indefinite, 25)\}

R2 When a noun phrase is estimated to be a definite noun phrase, and satisfies the modifier and possessor constraints, and the same noun phrase $\mathrm{X}$ has already appeared, $\{($ The noun phrase $\mathrm{X}, 30)\}$

R3 When a noun phrase is estimated to be a generic noun phrase, $\{($ Generic, 10$)\}$

R4 When a noun phrase is estimated to be an indefinite noun phrase, $\{($ Indefinite, 10) $\}$

R5 When a noun phrase $\mathrm{X}$ is not estimated to be a definite noun phrase,

$\{$ (A noun phrase $\mathrm{X}$ which satisfies the modifier and possessor constraints, $P+W-D+4)\}$

The values $P, W, D$ are as defined in Section 3.1 .

\section{Experiment and Discussion}

\subsection{Experiment}

Before determining the referents of noun phrases, sentences were at first transformed into a case structure by the case structure analyzer (Kurohashi and Nagao 1994). The errors made by the case analyzer were corrected by hand. Table 1 shows the results of determining the referents of noun phrases.

To confirm that the three constraints (referential property, modifier, and possessor) are effective, we experimented under several different conditions and compared them. The results are shown in Table 2. Precision is the fraction of noun phrases which were judged to have antecedents. Recall is the fraction of noun phrases which have antecedents.

In these experiments we used training sentences and test sentences. The training sentences were used to make the heuristic rules in Section 4.2 by hand. The test sentences were used to confirm the effectiveness of these rules.

In Table 2, Method 1 is the method mentioned in Section 3 which uses all three constraints. Method 2 is the case in which a noun phrase can refer to the entity denoted by a noun phrase, only when the estimated referential property is a definite noun phrase, where the modifier and possessor constraints are used. Method 3 does not use a referential property. It only uses information such as distance, topicfocus, modifier, and possessor. Method 4 does not use the modifier and possessor constraints.

The table shows many results. In Method 1, both the recall and the precision were relatively high in comparison with the other methods. This indicates that the referential property was used properly in the method that is described in this paper. Method 1 was higher than Method 3 in both recall and precision. This indicates that the information of referential property is necessary. In Method 2, the recall was low because there were many noun phrases that were definite but were estimated to be indefinite or generic, and the system estimated that the noun phrases cannot refer to noun phrases. In Method 4, the precision was low. Since the modifier and possessor constraints were not used, and there were many pairs of two noun phrases that did not corefer, such as "HIDARI(left)-NO HOO(cheek)" and "MIGI(right)-NO HOO(cheek)", these pairs were incorrectly interpreted to be co-references. This indicates that it is necessary to use the modifier and possessor constraints.

\subsection{Examples of Errors}

We found that it was necessary to use modifiers and possessors in the experiments. But there are some cases when the referent was determined incorrectly because the possessor of a noun was estimated incorrectly. 
Table 1: Results

\begin{tabular}{|l|c|c|}
\hline & Precision & Recall \\
\hline Training sentences & $82 \%(130 / 159)$ & $85 \%(130 / 153)$ \\
Test sentences & $79 \%(89 / 113)$ & $77 \%(89 / 115)$ \\
\hline
\end{tabular}

Training sentences (example sentences ( 43 sentences), a folk tale "KOBUTORI JIISAN" (Nakao 1985) (93 sentences), an essay in "TENSEIJINGO" (26 sentences), an editorial ( 26 sentences), an article in "Scientific American (in Japanese)" (16 sentences)\}

Test sentences \{a fork tale "TSURU NO ONGAESHI" (Nakao 1985) (91 sentences), two essays in "TENSEIJINGO" ( 50 sentences), an editorial (30 sentences), "Scientific American(in Japanese)" (13 sentences)\}

Table 2: Comparison

\begin{tabular}{|l|l|c|c|c|c|}
\hline \multicolumn{2}{|c|}{} & Method 1 & Method 2 & Method 3 & Method 4 \\
\hline Training sentences & Precision & $82 \%(130 / 159)$ & $92 \%(117 / 127)$ & $72 \%(123 / 170)$ & $65 \%(138 / 213)$ \\
& Recall & $85 \%(130 / 153)$ & $76 \%(117 / 153)$ & $80 \%(123 / 153)$ & $90 \%(138 / 153)$ \\
\hline Test sentences & Precision & $79 \%(89 / 113)$ & $92 \%(78 / 85)$ & $69 \%(79 / 114)$ & $58 \%(92 / 159)$ \\
& Recall & $77 \%(89 / 115)$ & $68 \%(78 / 115)$ & $69 \%(79 / 115)$ & $80 \%(92 / 115)$ \\
\hline
\end{tabular}

Method 1: The method used in this work

Method 2: Only when it is estimated to be definite can it refer to the entity denoted by a noun phrase

Method 3: No use of referential property

Method 4 : No use of modifier constraint and possessor constraint

Sometimes a noun can refer to the entity denoted by a noun that has a different modifier. In such cases, the system made an incorrect judgment.

\section{OJIISAN-WA CHIKAKU-NO OOKINA SUGI-NO (old man) (near) (huge) (cedar) \\ II-NO NEMOTO-NI ARU ANA-DE \\ (tree) (base) (be at) (hole) \\ AMAYADORI-WO SURU-KOTO-NI-SHITA. \\ (take shelter from the rain) (decide to do) \\ (So, he decided to take shelter from the rain in a hole which is at the base of a huge cedar tree nearby.)}

(an omission of the middle part)

TSUGI-NOHI, KONO OJIISAN-WA YAMA-HE ITTE, (next day) (this) (old man) (mountain) (go to) (The next day, this man went to the mountain,)

\section{SUGI-NO KI-NO NEMOTO-NO ANA-WO MITSUKETA.} (cedar) (tree) (at base) (hole) (found) (and found the hole at the base of the cedar tree.)

The two instances of "ANA (hole)" in these sentences refer to the same entity. But our system judged that they do not refer to it because the modifiers of the two instances of "ANA (hole)" are different. In order to correctly analyze this case, it is necessary to decide whether the two different expressions are equal in meaning.

\section{Summary}

This paper describes a method for the determination of referents of noun phrases by using their referential properties, modifiers, and possessors. Using this method on training sentences, we obtained a precision rate of $82 \%$ and a recall rate of $85 \%$ in the determination of referents of noun phrases that have antecedents. On test sentences, we obtained a precision rate of $79 \%$ and a recall rate of $77 \%$. This confirmed that the use of the referential properties, modifiers, and possessors of noun phrases is effective.

\section{References}

Sadao Kurohashi, Makoto Nagao. 1994. A Method of Case Structure Analysis for Japanese Sentences based on Examples in Case Frame Dictionary. the Institute of Electronics, Information and Communication Enginners Transactions on Information and Systems $E 77-D(2)$, pages 227-239.

Masaki Murata, Makoto Nagao. 1993. Determination of referential property and number of nouns in Japanese sentences for machine translation in to English. In Proceedings of the 5th TMI, pages 218-225, Kyoto, Japan, July.

Kiyoaki Nakao. 1985. The Old Man with a Wen. Eiyaku Nihon Mukashibanashi Series, Vol. 7, Nihon Eigo Kyouiku Kyoukai (in Japanese).

Yasuhiko Watanabe, Sadao Kurohashi, Makoto Nagao. 1992. Construction of semantic dictionary by IPAL dictionary and a thesaurus, (in Japanese). In Proceedings of the 45th Convention of IPSJ, pages 213-214, Tokushima, Japan, July. 